\title{
Cholinesterase inhibitors as Alzheimer's therapeutics (Review)
}

\author{
KAMLESH SHARMA \\ Department of Chemistry, Faculty of Physical Sciences, Shree Guru Gobind Singh Tricentenary University, \\ Gurugram, Haryana 122505, India
}

Received October 23, 2018; Accepted May 9, 2019

DOI: $10.3892 / \mathrm{mmr} .2019 .10374$

\begin{abstract}
Alzheimer's disease (AD) is one of the most common forms of dementia. AD is a chronic syndrome of the central nervous system that causes a decline in cognitive function and language ability. Cholinergic deficiency is associated with AD, and various cholinesterase inhibitors have been developed for the treatment of $\mathrm{AD}$, including naturally-derived inhibitors, synthetic analogues and hybrids. Currently, the available drugs for AD are predominantly cholinesterase inhibitors. However, the efficacy of these drugs is limited as they may cause adverse side effects and are not able to completely arrest the progression of the disease. Since AD is multifactorial disease, dual and multi-target inhibitors have been developed. The clinical applications and the limitations of the inhibitors used to treat AD are discussed in the present review. Additionally, this review presents the current status and future directions for the development of novel drugs with reduced toxicity and preserved pharmacological activity.
\end{abstract}

\section{Contents}

1. Introduction

2. Acetylcholinesterase

3. Traditional ChE inhibitors

4. Next generation ChE inhibitors

5. Naturally-derived inhibitors

6. Hybrid inhibitors

7. Synthetic analogues

8. Future directions

9. Conclusions

Correspondence to: Dr Kamlesh Sharma, Department of Chemistry, Faculty of Physical Sciences, Shree Guru Gobind Singh Tricentenary University, Gurgaon-Badli Road Chandu, Budhera, Gurugram, Haryana 122505, India

E-mail: drkamlesh_fps@sgtuniversity.org

Key words: Alzheimer's, dementia, cholinesterase, inhibitor, multi-target

\section{Introduction}

Alzheimer's disease (AD) accounts for $60-70 \%$ of cases of dementia worldwide, with an estimated global incidence of 24.3 million cases. AD is a chronic syndrome that causes progressive deterioration of the central nervous system (CNS). $\mathrm{AD}$ causes progressive deficits in decision making, language, memory, learning, orientation and judgement (1). The major risk factor for AD is aging (2). However, physical exercise can decrease the rate of dementia (3).

The enzyme cholinesterase (ChE) is a significant therapeutic target for AD (4). The deterioration of cholinergic neurons in the brain and the loss of neurotransmission are the major causes of the decline in cognitive function in patients with AD (5).

According to the cholinergic hypothesis (5), the main cause of $\mathrm{AD}$ is the reduction in acetylcholine (ACh) synthesis. Therefore, one of the potential therapeutic strategies is to increase the cholinergic levels in the brain by inhibiting the biological activity of acetylcholinesterase (AChE). Therefore, $\mathrm{AChE}$ inhibitors are used to limit the degradation of ACh. $\mathrm{AChE}$ inhibitors are able to increase the function of neural cells by increasing the concentration of ACh (6).

The progressive synthesis and aggregation of $\beta$-amyloid $(\mathrm{A} \beta)$, a proteolytic fragment derived from amyloid precursor protein (APP), are additional critical factors involved in AD pathogenesis (7). Therefore, tacrine hybrids (8-10) and donepezil-based (11) dual inhibitors have been developed to inhibit both AchE activity and $\mathrm{A} \beta$ aggregation. Computational approaches have been used to design various dual inhibitors of $\mathrm{AChE}$ and A $\beta$ cleaving enzyme 1 (12).

In addition, tauopathy is an important aspect of AD pathology, and $\tau$ protein hyperphosphorylation leads to the formation of intracellular neurofibrillary tangles of the microtubule-associated protein $\tau$ and subsequent neurodegeneration $(13,14)$. Therapies targeting $\tau$ protein reduce and prevent its hyperphosphorylation and aggregation (15-17). Several drugs under development are in phase III clinical trials, including methylthioninium, which inhibits $\tau$ phosphorylation by activating the $\tau$ phosphatases or by inhibiting $\tau$ kinases $(18,19)$.

Since AD is a multifactorial disorder, researchers have turned their attention to developing multi-target drugs to inhibit multiple factors involved in $\mathrm{AD}$, including protein misfolding and associated $\mathrm{A} \beta$ aggregation, $\tau$ aggregation, metal dyshomeostasis, oxidative stress and the decreased 
ACh levels. However, few studies have been done to identify multi-target AD drugs $(20,21)$.

\section{Acetylcholinesterase}

AChE (EC 3.1.1.7) (22) is an important enzyme involved in the cholinergic nervous system, which includes the peripheral nervous system and the CNS. AChE catalyses the hydrolysis of ACh to generate choline and acetate ions (Fig. 1). The active site of AChE is a large hydrophobic cavity. AChE consists of two subsites: i) The esteratic subsite (ES); and ii) the anionic substrate binding site (AS). ACh is a widely distributed neurotransmitter in the CNS. The AS binds to the positively charged quaternary amine of $\mathrm{ACh}$, and can bind to other cationic substrates and inhibitors $(22,23)$. The ES contains a catalytic triad consisting of Ser200, Glu327 and His440 (24). The catalytic triad is located $20 \AA$ from the enzyme surface, at the bottom of a narrow gorge that widens towards the base. As a part of the catalytic triad, Ser200 is responsible for the hydrolysis of choline esters by proton transfer $(22,23)$. Additionally, the cation- $\pi$ interaction is present between an aromatic amino acid and the quaternary ammonium of ACh (22).

The peculiar structural feature of the active site in the Torpedo californica AChE (TcAChE), a prototypical ACh-binding protein, consists of the presence of a high number of aromatic residues ( 14 amino acids) (25). Trp84 is the most important aromatic amino acid for the AChE-ACh interaction, and its substitution with alanine results in a 3,000-fold decrease in reactivity (26). In addition to these sites, AChE possesses an 'acyl pocket', which confers substrate-specificity, and an 'oxyanion hole', which interacts with negative oxygen ions during catalysis, and increases the catalytic efficiency of AChE (27).

\section{Traditional ChE inhibitors}

A number of ChE inhibitors have been developed $(28,29)$. Donepezil, galantamine, rivastigmine and memantine are the four drugs used to treat AD currently available on the market (30-32). However, the efficacy of these drugs is limited, and these drugs have shown various dose-associated side-effects, particularly at higher doses $(28,29)$. Galantamine and donepezil are AChE inhibitors (28), whereas rivastigmine is a reversible inhibitor of both $\mathrm{AChE}$ and butyrylcholinesterase (BChE). Notably, donepezil is highly selective for AChE compared with BChE. The AChE inhibitory potencies ( $\mathrm{IC}_{50}$ values) of tacrine, donepezil, rivastigmine and physostigmine are $77,6.7,4.3$ and $0.67 \mathrm{nM}$, respectively (29).

Physostigmine. Eserine, also known as physostigmine, was first isolated from Calabar beans in 1864 (33) and is an AChE inhibitor (34). Although physostigmine can cross the blood-brain barrier (BBB), this drug has a narrow therapeutic index due to its short half-life and numerous side effects (35). Its common side effects include diarrhoea, stomach cramps, increased production of saliva and excessive sweating (35). Due to these disadvantages, physostigmine was not approved for the treatment of AD. The structure of physostigmine is presented in Fig. 2A.
Tacrine. Tacrine was first synthesized in the 1930s, and was originally used as a muscle relaxant antagonist and respiratory stimulant (36). Tacrine has been used in patients with AD sincethe 1980s, having been approved by the FDA in 1993 and discontinued in 2013. The molecular structure of the drug is presented in Fig. 2B. Tacrine interacts with the amino acid residues Phe330 and Trp84, which are present in the 'anionic site' of AChE (37). Tacrine is an effective inhibitor of both $\mathrm{AChE}$ and BChE (38). However, the use of tacrine is limited due to its many side effects, including nausea, vomiting, loss of appetite, diarrhoea and clumsiness (39). In addition, patients treated with tacrine require blood monitoring due to the hepatotoxicity induced by this drug. Additionally, multiple-dosage regimens are required to maintain prolonged therapeutic activity, due to the short half-life of tacrine and its adverse side effects at high dosage (40). Tacrine was discontinued due to the aforementioned side effects and liver toxicity.

Donepezil. In 1996, the drug donepezil was approved for the treatment of mild to moderate AD (30) (Fig. 2C). However, donepezil presents various side effects, including insomnia, nausea, loss of appetite, diarrhoea, muscle cramps and muscle weakness (41). Patients treated with high doses of donepezil suffer from low blood pressure, severe vomiting, muscle weakness, severe nausea, breathing problems and bradycardia (41). In addition to inhibit $\mathrm{ChE}$, donepezil may have additional mechanisms of action (42). Donepezil not only acts at the neurotransmitter level, but also at the molecular and cellular level in almost all stages involved in the pathogenesis of $\mathrm{AD}$, including the inhibition of various aspects of glutamate-induced excitotoxicity, the reduction of early expression of inflammatory cytokines, the induction of a neuroprotective isoform of $\mathrm{AChE}$ and the reduction of oxidative stress-induced effects (42). Donepezil exhibits a unique molecular structure that causes the simultaneous inhibition of the active and the peripheral anionic sites (PAS) of TcAChE (43). However, donepezil does not directly interact with the oxyanion hole or the catalytic triad (43).

Rivastigmine. Rivastigmine was approved for the treatment of mild to moderate AD in 2000. In addition, this drug has been used for the treatment of Parkinson's disease-associated dementia (44). Although the exact mechanism of action of rivastigmine is unclear, it was hypothesized that it may exert its pharmacological action by increasing cholinergic function (32). Rivastigmine tartrate targets both $\mathrm{BChE}$ and AChE. Rivastigmine tartrate is a carbamate that binds to $\mathrm{AChE}$, which cleaves rivastigmine into various phenolic derivatives that are rapidly excreted from the body (45). The carbamate moiety binds to the ES of AChE with more affinity than that of the acetate moiety of ACh during $\mathrm{ACh}$ hydrolysis. Therefore, the enzyme is inactivated for a certain amount of time (45). This effect may explain its unusually slow activation kinetics (32). Rivastigmine has major side effects, including stomach pain, weight loss, diarrhoea, loss of appetite, nausea and vomiting (46). An overdose of rivastigmine may cause numerous symptoms, including irregular, fast or slow breathing, chest pain, and slow or irregular heartbeat (46). The structure of rivastigmine is presented in Fig. 2D. 
<smiles>CC(=O)OCC[N+](C)(C)C(C)C(C)=O</smiles>

Figure 1. Schematic representation of AChE catalysis. AChE, acetylcholinesterase.

A<smiles>CNC(=O)Oc1ccc2c(c1)[C@]1(C)CCN(C)[C@@H]1N2C</smiles>

Physostigmine
B<smiles>Nc1c2c(nc3ccccc13)CCCC2</smiles>

Tacrine<smiles>COc1cc2c(cc1OC)C(=O)C(CC1CCN(Cc3ccccc3)CC1)C2</smiles><smiles>[2H][C@H](C)c1cccc(OC(=O)N(C)CC)c1</smiles>

Rivastigmine

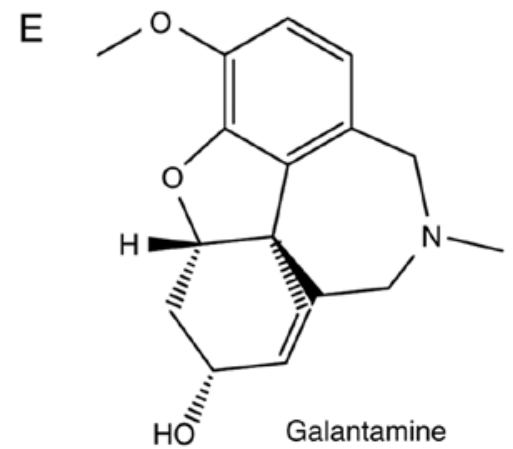

$\mathrm{F}$<smiles>COP(=O)(OC)C(O)C(Cl)(Cl)Cl</smiles>

Metrifonate

Figure 2. Traditional cholinesterase inhibitors. The molecular structures of (A) physostigmine, (B) tacrine, (C) donepezil, (D) rivastigmine, (E) galantamine and $(\mathrm{F})$ metrifonate are presented.

Galantamine. Galantamine is an alkaloid present in many plants, including daffodil bulbs (47). Galantamine has been used as a medicine in Russia and Eastern European countries for decades for the treatment of myopathy, myasthenia, and sensory and motor deficits associated with the CNS (48). Galantamine has also been shown to bind to nicotinic cholinergic receptors. Its activity against $\mathrm{ChE}$ was identified in the 1950s; it has been marketed with the name Nivalin and used for the treatment of several neurological diseases (49). Galantamine was approved for the treatment of AD in 2001 (31). The chemical structure of galantamine is presented in Fig. 2E. Galantamine has been shown to be effective in treating the cognitive symptoms of AD. Notably, a gradual increase in galantamine dosage may increase the tolerability of this drug (50). The main side effects of galantamine include convulsions, severe nausea, stomach cramps, vomiting, irregular breathing, confusion, muscle weakness and watering eyes (51).

Metrifonate. Metrifonate (Fig. 2F) is a long-acting organophosphate AChE inhibitor, and it is used for the treatment of schistosomiasis (52). Metrifonate can improve cholinergic neurotransmission via a pharmacologically active metabolite, 
2,2-dichlorovinyl dimethyl phosphate, and has been tested for the treatment of AD (53). Metrifonate administered once per day can improve the cognitive function of patients with mild to moderate AD (53). The tolerability of metrifonate is good, but its long-term use cause adverse side effects, including problems with neuromuscular transmission and respiratory paralysis (25). Therefore, the development of this drug was interrupted during Phase III clinical trials.

\section{Next-generation ChE inhibitors}

Physostigmine derivatives, such as phenserine, tolserine and eseroline, have been developed as ChE inhibitors.

Phenserine. Phenserine is a selective, non-competitive AChE inhibitor that not only inhibits AChE, but also reduces the production of APP in vitro and in vivo (54). Additionally, the toxicity of phenserine is lower compared with that of tacrine and physostigmine (55). Notably, treatment with phenserine was shown to improve memory and learning in aged dogs and rats (54). Phenserine was clinically tested for AD, but has shown only moderate success in initial Phase II clinical trials (54).

Phenserine was observed to be a promising agent for the development of novel strategies for the treatment of AD due to its dual anti-A $\beta$ and anti-AChE effects. However, in 2005, the biopharmaceutical company Axonyx, Inc. announced that phenserine was ineffective in two curtailed Phase III clinical trials (56). Furthermore, in 2010, a previous study demonstrated that high doses of phenserine may improve the symptoms of patients with mild to moderate AD (57). In 2016, it was demonstrated that phenserine also exhibits non-cholinergic effects with clinical potential. Phenserine was used for the treatment of cognitive impairments induced by traumatic brain injury in mice (58). Notably, clinical trials and the investigation of its mechanisms are currently under development (59). The structure of phenserine is presented in Fig. 3A.

Tolserine. The structure of tolserine slightly differs from that of phenserine by the presence of a 2-methyl group in its phenylcarbamoyl moiety (Fig. 3B). In 2000, preclinical studies concluded that tolserine is 200 -fold more selective against human AChE (hAChE) compared with BChE. The inhibitory concentration of tolserine against AChE in human erythrocytes is $0.01 \mu \mathrm{M}(60)$. Furthermore, its inhibitory concentration against human $\mathrm{AChE}$ in red blood cells pre-treated for $30 \mathrm{~min}$ using the Ellman technique is $0.0103 \mu \mathrm{M}(61)$. The potency of tolserine against $\mathrm{hAChE}$ is higher compared with that of phenserine or physostigmine (62). However, its side effects or benefits in clinical and preclinical models are unclear.

Eseroline. Eseroline acts as an opioid agonist (63). In 1982 , it was demonstrated that eseroline is a metabolite of physostigmine; however, in contrast to physostigmine, the effect of eseroline on AChE inhibition is limited and reversible (64). Various physostigmine analogues have been analysed for $\mathrm{ChE}$ inhibition (65). A cyclic alkyl carbamate derived from eseroline (Fig. 3C) was found to be effective against AChE with high selectivity compared with BChE (65). However, to the
A

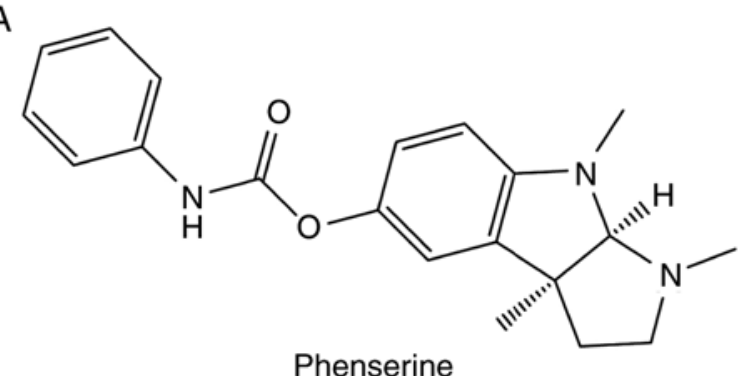

Phenserine

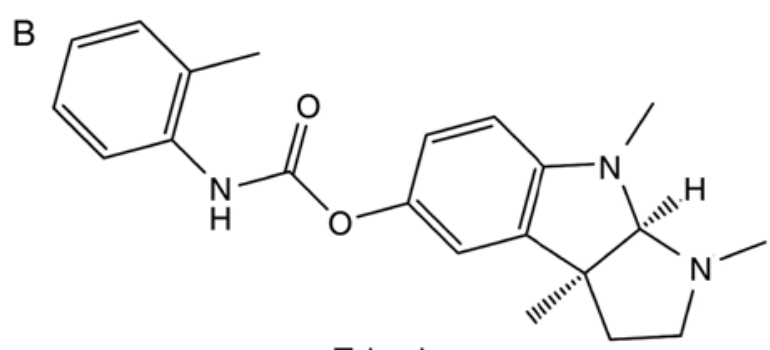

Tolserine

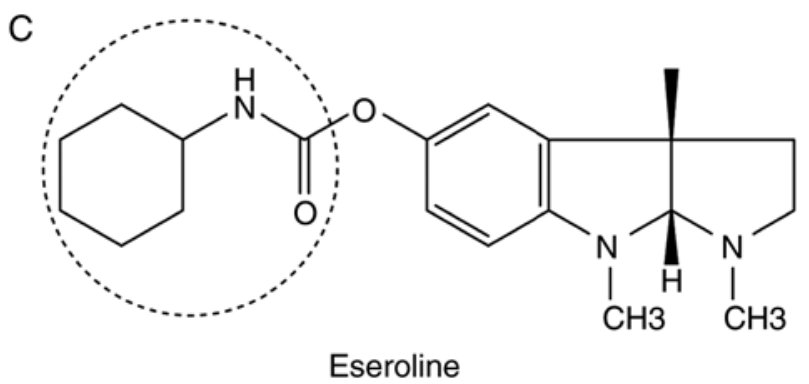

Figure 3. Novel cholinesterase inhibitors. The molecular structures of (A) phenserine, (B) tolserine and (C) eseroline are presented. The circle indicates the active moiety of eseroline.

best of the author's knowledge, no recent studies have reported on the effects of eseroline.

\section{Naturally-derived inhibitors}

Huperzine (Hup). Hup is a lycopodium alkaloid. Hup can be extracted and isolated from the herb Huperzia serrata (66). In total, two types of Hup are present: Hup-A and Hup-B (Fig. 4A and $\mathrm{B}$, respectively). Hup-B is a natural homologue of Hup-A, which is used for the treatment of AD and age-related memory impairment, and for memory and learning enhancement, as it increases the level of ACh (67). Hup-A is more effective than rivastigmine, galantamine and tacrine (67). Hup-A is a highly selective and potent inhibitor of AChE. However, it is less active against BChE compared with AChE. Tacrine-Hup-A hybrids have shown potential AChE-inhibiting effects (67).

A prodrug of Hup-A called ZT-1 is under development for the treatment of AD. Both Hup-A and -B interact in similar ways with AChE (68). Both Hup molecules interact with anionic sites via $\pi-\pi$ stacking, and with $\operatorname{Trp} 84$ and Phe330 via $\mathrm{CH} / \pi$-interactions or van der Waals forces (68). The $\alpha$-pyridone moiety of Hup interacts with the active site of $\mathrm{AChE}$ via $\mathrm{CH} / \pi$-interactions and $\mathrm{H}$-bonds. The carbonyl oxygen of Hup repels the carbonyl oxygen of Gly117. As a result, the peptide bond between Gly118 and Gly117 flips (68). Furthermore, the flipped peptide plane conformation is 


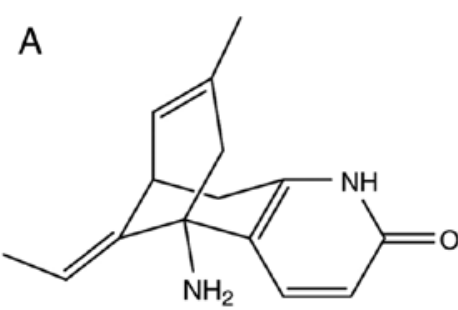

Huperzine A<smiles>O=c1c(O)c(-c2ccccc2)oc2cc(O)cc(O)c12</smiles>

Galangin
B

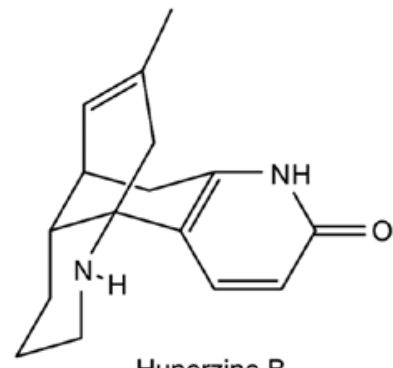

Huperzine B

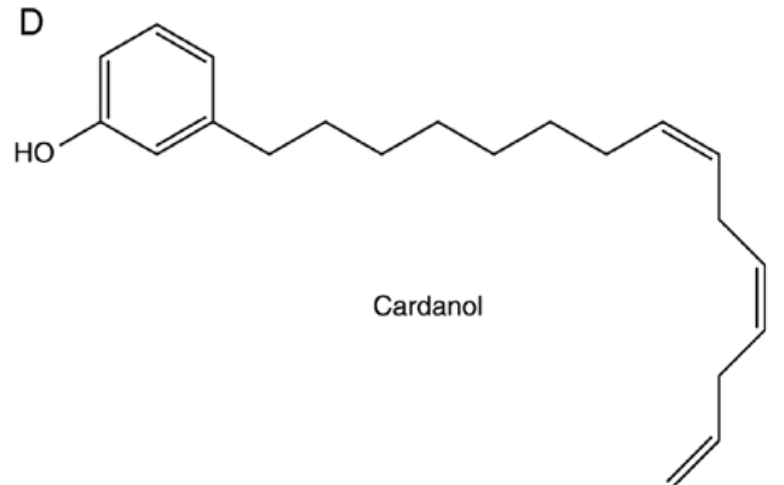

Figure 4. Naturally-derived cholinesterase inhibitors. The molecular structures of (A) huperzine A, (B) huperzine B, (C) galangin and (D) cardanol are presented.

stabilized by H-bonds between the oxygen of Gly117 with the nitrogen atoms of Ala201 and Gly119 (68). However, Hup-A may cause mild cholinergic side effects such as nausea, vomiting and diarrhoea (69).

Flavonoid. Flavonoids have attracted great interest due to their free-radical-scavenging properties. A series of flavonoid compounds have shown effective AChE inhibitory activities in vitro (70). Galangin, a flavonol derived from the rhizomes of Alpiniae officinarum, has shown potent inhibitory activity against AChE (Fig. 4C) (70). However, the toxicity of these flavonoids have not been investigated in preclinical and clinical trials, and no human trials have been reported.

Cardanol. In 2009, various non-isoprenoid phenolic lipids obtained from Anacardium occidentale were investigated for their inhibitory activity against AChE (71). In particular, cardanol, a phenolic lipid, has shown promising results (71). Moreover, cardanol can be extracted from cashew nut shells (72). However, its toxicity has not yet been investigated in preclinical and clinical trials. The molecular structure of cardanol is presented in Fig. 4D.

\section{Hybrid inhibitors}

Donepezil-AP2238 hybrid. AP2238 was the first developed drug with dual binding sites, and it is able to interact with both anionic sites of AChE (73). The activities of AP2238 and donepezil against $\mathrm{AChE}$ are similar. However, the effect of AP2238 in inhibiting A $\beta$-mediated toxicity is higher (73). Therefore, a series of donepezil-AP2238 hybrids have been investigated (74). The structure of a donepezil-AP2238 hybrid is presented in Fig. 5A. Out of 22 compounds
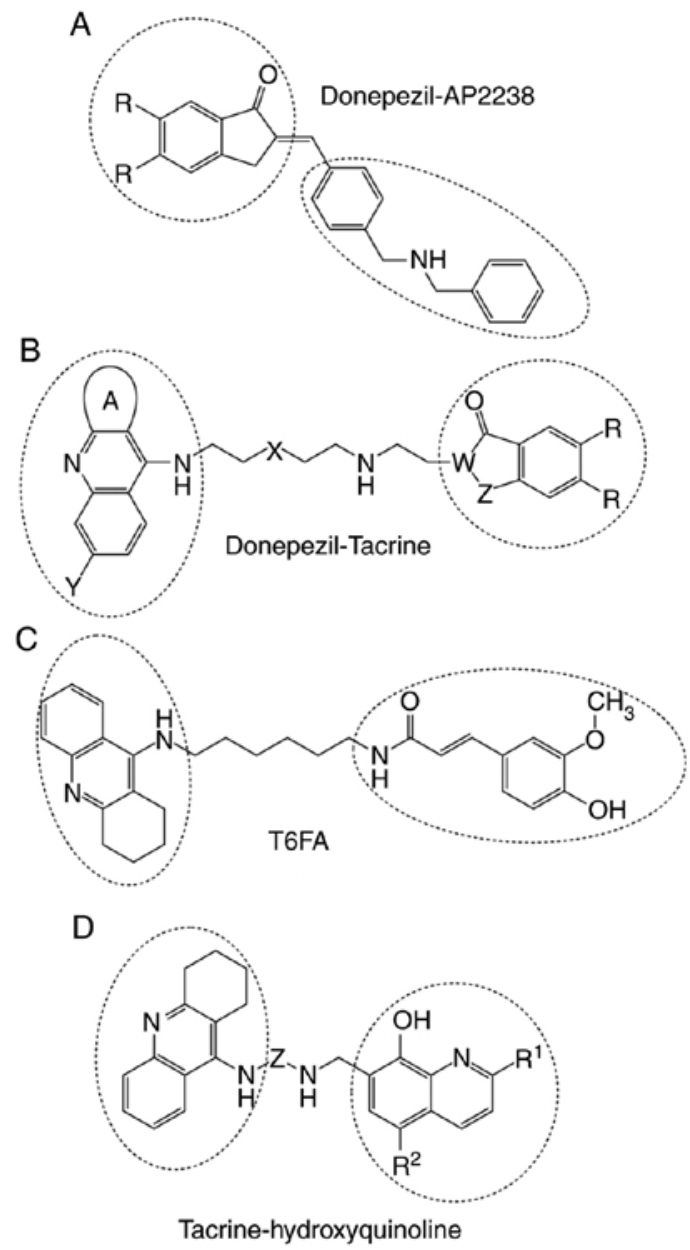

Figure 5. Hybrid cholinesterase inhibitors. The molecular structures of (A) donepezil-AP2238,(B)donepezil-tacrine,(C) T6FA and(D) tacrine-hydroxyquinoline are presented. The drugs forming the hybrids are indicated by circles. 
A<smiles>[R]Nc1c2c(nc3ccc(OC)cc13)CCCC2</smiles>

C<smiles>[R]C(=O)C1Cc2cc(OC)c(OC)cc2C1=O</smiles>

B<smiles>N#C/C(=C\c1cccnc1)c1nc2ccccc2s1</smiles>

Ladostigil

Figure 6. Synthetic analogues of cholinesterase inhibitors. (A) Tacrine analogue, (B) heteroarylacrylonitrile derivative, (C) indenyl derivative and (D) Ladostigil.

investigated (74), two molecules have shown potent activities. Both compounds have an alkyl chain of five carbon atoms and an amino group present at the end of the chain, which results in an increased interaction with the PAS of AChE (74).

Donepezil-tacrine hybrid. Camps et al (11) designed a series of donepezil-tacrine hybrids (Fig. 5B), which interact simultaneously with the active, peripheral and mid-gorge binding sites of $\mathrm{AChE}$. These hybrids were found to inhibit $\mathrm{AChE}, \mathrm{BChE}$ and $\mathrm{A} \beta$-aggregation induced by AChE. Donepezil-tacrine hybrids are synthesized by combining 6-chlorotacrine with the indanone moiety of donepezil, and are more effective at inhibiting hAChE compared with their parent compounds (11).

Tacrine-ferulic acid (T6FA) hybrid. T6FA hybrid has shown more potent AChE-inhibitory effects compared with tacrine, and inhibits BChE at comparable levels (Fig. 5C). T6FA has shown potent activity in inhibiting $A \beta$-mediated $\mathrm{AD}$-associated pathogenesis in vitro and in vivo (75).

Tacrine and 8-hydroxyquinoline hybrids. Tacrine and 8-hydroxyquinoline hybrids are drugs that inhibit cholinesterase and reduce $A \beta$ aggregation by forming complexes with redox-active metals (Fig. 5D). These hybrids inhibit AChE more effectively than tacrine alone, and have been shown to have increased CNS permeability, low toxicity, and antioxidant and copper complexing properties (38).

L-monoamine oxidases (MAOs) (EC 1.4.3.4) catalyse the oxidation of monoamines $(76,77)$. Recently, a donepezil-chromone-melatonin hybrid has been developed as a multi-target agent with strong $\mathrm{BChE}$ and moderate hAChE inhibitory capacities, and with anti-MAO-A/B and antioxidant properties (78). Furthermore, tacrine-acridine hybrids have been developed as multi-target drugs for the treatment of AD (79). In addition, tacrine-carbohydrate (80) and tacrin-T6FA (81) hybrids have shown potent ChE inhibitory potential.

\section{Synthetic analogues}

Synthetic analogues have been developed as competitive ChE inhibitors, since gastrointestinal side effects and hepatotoxicity can be avoided with targeted pharmacological development (82). However, the main problem of synthetic analogues is that they may not permeate the BBB and their effectiveness can be lower compared with naturally derived ChE inhibitors (83).

Tacrine analogues. N-alkyl-7-methoxytacrine hydrochloride (Fig. 6A), an analogue of tacrine, has shown improved AChE-inhibitory activities compared with the parent drug tacrine (84).

(E)-2(benzo[d]thiazol-2-yl)-3-heteroarylacrylonitriles. (E)2(Benzo[d]thiazol-2-yl)-3-heteroarylacrylonitriles have been in development as AChE inhibitors since 2012 (Fig. 6B) (84). The most potent compound among them was found to be more selective to AChE than galanthamine.

Indenyl derivatives. Various analogues of phenyl5,6-dimethoxy-1-oxo-2,3-dihydro-1H-2-indenylmethanone were synthesized and tested by Ali et al in 2009 (83). Most of them showed moderate AChE-inhibitory effects. Ali et al (83) suggested that the presence of methoxy groups on the phenyl ring significantly improved the inhibition of AChE (Fig. 6C).

Ladostigil. Ladostigil is a potent anti-AD drug with AChE-inhibitory and neuroprotective properties (Fig. 6D). Ladostigil [(N-propargyl-(3R) aminoindan-5yl)-ethyl methyl carbamate)] is in Phase IIb trials (85).

Recently, 1,2,4-triazine scaffolds (86) and 1,2,3-triazolechromenone carboxamide derivatives (87) have been developed as multi-target therapeutic agents for the treatment of AD. Chalcone-based derivatives have shown $\mathrm{ChE}$-inhibitory properties (88). Chromone scaffolds have shown dual inhibition of $\mathrm{ChE}$ and MAO (89). Various donepezil-based multi-functional ChE inhibitors have been developed for the treatment of AD (90). 


\section{Future directions}

Since the discovery of the first AchE inhibitor, physostigmine (30), a large number of studies have been performed to identify more effective inhibitors. Traditional inhibitors are naturally-derived agents. Other inhibitors include analogues of the traditional inhibitors, derivatives of natural compounds and hybrids of synthetic inhibitors. These inhibitors cause milder side effects than traditional drugs and may have improved properties, such as better BBB permeability and increased effectiveness $(11,67)$. In addition, these compounds are able to limit the progression of $\mathrm{AD}$. Recent reports investigated $\mathrm{AChE}$ inhibition $(80,88,90)$, but only a few novel drugs have been tested in humans $(18,60-62,78)$. Most of these inhibitors have been studied in animal models, or using in vitro and in silico models. Therefore, further studies in humans to investigate the safety, efficacy and toxicity of these drugs are required.

AChE inhibitors are not able to completely stop the progression of $\mathrm{AD}$, and various single-target drugs that have reached clinical trials were not able to effectively treat AD. Therefore, there is a need to develop multi-functional drugs that are able to target all symptoms of $\mathrm{AD}$, including the decreased levels of $\mathrm{ACh}$, protein misfolding and associated $\mathrm{A} \beta$ aggregation, hyperphosphorylation of $\tau$ protein, metal dyshomeostasis and oxidative stress. However, only a limited number of studies have focused on the development of multi-target drugs $(79,81,89)$.

According to structure-activity relationship studies, the design of novel potent multi-target inhibitors should have the following characteristics: i) The presence of a nitrogen atom with a positive charge $(91)$; ii) the size of the alkyl chain attached to the nitrogen atom should be small, such as a methyl group (92); iii) the presence of an oxygen atom able to form hydrogen bonds, such as an ester (93); iv) the presence of electron-donating groups such as hydroxyl and methoxy groups (83); and v) the presence of a two-carbon unit between nitrogen and oxygen atoms (91). Notably, the overall size of the molecule should be small, since large molecules can exhibit decreased activity (94).

\section{Conclusions}

The present review provided an overview of the $\mathrm{ChE}$ and $\mathrm{AChE}$ inhibitors that have been developed to treat AD. These inhibitors include naturally-derived inhibitors, synthetic analogues and hybrids. Although ChE inhibitors do not cure AD, these drugs are recommended to limit neurodegeneration in patients with AD. Since current ChE inhibitors can cause several side effects, the development of novel agents with different structures and mechanisms of action is required. Since AD is a multifactorial disease, multi-target inhibitors should be developed. Therefore, future approaches should be focused on the development of a single molecule able to target multiple factors involved in $\mathrm{AD}$. To the best of the author's knowledge, only a limited number of studies have used this approach. The development of a multi-target drug is a challenging task that can be accomplished by using computational approaches, including molecular modelling and molecular docking (95). These methods can provide helpful insights into the design of novel inhibitors, reducing the time and costs of development. The present review may be helpful to medicinal chemists and to the pharmaceutical industry in designing and developing novel drugs for the treatment of AD.

\section{Acknowledgements}

The author would like to thank the Faculty of Physical Sciences, SGT University, for providing facilities.

\section{Funding}

No funding was received.

\section{Availability of data and materials}

Not applicable.

\section{Authors' contributions}

KS designed the review, conducted literature search, wrote and revised the manuscript, read and approved the final manuscript.

\section{Ethics approval and consent to participate}

Not applicable.

\section{Patient consent for publication}

Not applicable.

\section{Competing interests}

The author declares no competing interests.

\section{References}

1. Khachaturian ZS: Diagnosis of alzheimer's disease. Arch Neurol 42: 1097-1105, 1985.

2. Kuhn D: New horizons. Contemporary longterm care 26: 25-26, 2003.

3. Cheng ST: Cognitive reserve and the prevention of dementia: The role of physical and cognitive activities. Curr Psychiatry Rep 18: 85, 2016.

4. Silman I and Sussman JL: Acetylcholinesterase: Classical and non-classical functions and pharmacology. Curr Opin Pharmacol 5: 293-302, 2005.

5. Bartus RT, Dean RL III, Beer B and Lippa AS: The cholinergic hypothesis of geriatric memory dysfunction. Science 217: 408-417, 1982.

6. Tabet N: Acetylcholinesterase inhibitors for alzheimer's disease: Anti-inflammatories in acetylcholine clothing. Age Ageing 35: 336-338, 2008.

7. Karran E, Mercken M and De Strooper B: The amyloid cascade hypothesis for Alzheimer's disease: An appraisal for the development of therapeutics. Nat Rev Drug Discov 10: 698-712, 2011.

8. Luo W, Li YP, He Y, Huang SL, Tan JH, Ou TM, Li D, Gu LQ and Huang ZS: Design, synthesis and evaluation of novel tacrine-multialkoxybenzene hybrids as dual inhibitors for cholinesterases and amyloid beta aggregation. Bioorg Med Chem 19: 763-770, 2011.

9. Tang H, Zhao LZ, Zhao HT, Huang SL, Zhong SM, Qin JK, Chen ZF, Huang ZS and Liang H: Hybrids of oxoisoaporphine-tacrine congeners: Novel acetylcholinesterase and acetylcholinesterase-induced $\beta$-amyloid aggregation inhibitors. Eur J Med Chem 46: 4970-4979, 2011.

10. Camps P, Formosa X, Galdeano C, Muñoz-Torrero D, Ramírez L, Gómez E, Isambert N, Lavilla R, Badia A, Clos MV, et al: Pyrano[3,2-c]quinoline-6-chlorotacrine hybrids as a novel family of acetylcholinesterase-and beta-amyloid-directed anti-Alzheimer compounds. J Med Chem 52: 5365-5379, 2009. 
11. Camps P, Formosa X, Galdeano C, Gómez T, Muñoz-Torrero D, Scarpellini M, Viayna E, Badia A, Clos MV, Camins A, et al: Novel donepezil-based inhibitors of acetyl- and butyrylcholinesterase and acetylcholinesterase-induced beta-amyloid aggregation. J Med Chem 51: 3588-3598, 2008.

12. Gupta S, Pandey A, Tyagi A and Mohan GA: Computational analysis of Alzheimer's disease drug targets. Curr Res Inf Pharm Sci 11: 1-10, 2010

13. Perl DP: Neuropathology of Alzheimer's disease. Mt Sinai J Med 77: 32-42, 2010.

14. Takashima A: Tau aggregation is a therapeutic target for Alzheimer's disease. Curr Alzheimer Res 7: 665-669, 2010.

15. Anand K and Sabbagh M: Early investigational drugs targeting tau protein for the treatment of Alzheimer's disease. Expert Opin Investig Drugs 24: 1355-1360, 2015.

16. Iqbal K, Gong CX and Liu F: Microtubule-associated protein tau as a therapeutic target in Alzheimer's disease. Expert Opin Ther Targets 18: 307-318, 2014

17. Noble W, Hanger DP, Miller CC and Lovestone S: The importance of tau phosphorylation for neurodegenerative diseases. Front Neurol 4: 83, 2013.

18. Panza F, Solfrizzi V, Seripa D, Imbimbo BP, Lozupone M, Santamato A, Zecca C, Barulli MR, Bellomo A, Pilotto A, et al: Tau-centric targets and drugs in clinical development for the treatment of Alzheimer's disease. Biomed Res Int 2016: 3245935 , 2016.

19. Congdon EE and Sigurdsson EM: Tau-targeting therapies for Alzheimer disease. Nat Rev Neurol 14: 399-415, 2018.

20. Russo P, Frustaci A, Del Bufalo A, Fini M and Cesario A Multitarget drugs of plants origin acting on Alzheimer's disease. Curr Med Chem 20: 1686-1693, 2013.

21. Azam F, Amer AM, Abulifa AR and Elzwawi MM: Ginger components as new leads for the design and development of novel multi-targeted anti-alzheimer's drugs: A computational investigation. Drug Des Devel Ther 8: 2045-2059, 2014.

22. Silman I and Sussman JL: Acetylcholinesterase: How is structure related to function? Chem Biol Interact 175: 3-10, 2008.

23. Lotta B: Targeting acetylcholinesterase: Identification of chemical leads by high throughput screening, structure determination and molecular modeling. PLoS One 6: e26039, 2011.

24. Tripathi A: Acetylcholinsterase: A versatile enzyme of nervous system. Ann Neurosci 15: 106-111, 2008.

25. López-Arrieta JM and Schneider L: Metrifonate for alzheimer's disease. Cochrane Database Sys Rev 2: 1-40, 2006.

26. Tougu V: Acetylcholinesterase: Mechanism of catalysis and inhibition. Curr Med Chem CNS Agents 1: 155-170, 2001.

27. Zhang Y, Kua J and McCammon JA: Role of the catalytic triad and oxyanion hole in acetylcholinesterase catalysis: An ab initio QM/MM study. J Am Chem Soc 124: 10572-10577, 2002.

28. Weinstock M: Selectivity of cholinesterase inhibition. CNS Drugs 12: 307-323, 1999

29. Ogura H, Kosasa T, Kuriya Y and Yamanishi Y: Comparison of inhibitory activities of donepezil and other cholinesterase inhibitors on acetylcholinesterase and butyrylcholinesterase in vitro. Methods Find Exp Clin Pharmacol 22: 609-613, 2000.

30. Rogers SL and Friedhoff LT: The efficacy and safety of donepezil in patients with Alzheimer's disease: Results of a US multicentre randomised double blind placebo-controlled trial The donepezil study group. Dementia 7: 293-303, 1996.

31. Olin J and Schneider L: Galantamine for Alzheimer's disease. Cochrane Database Syst Rev 4: CD001747, 2001.

32. Bar-On P, Millard CB, Harel M, Dvir H, Enz A, Sussman JL and Silman I: Kinetic and structural studies on the interaction of cholinesterases with the anti-Alzheimer drug rivastigmine. Biochem 41: 3555-3564, 2002.

33. Holmstedt B: In: Plants in the Development of Modern Medicine; Swain T (ed). Cambridge University Press, Cambridge, MA, p303 and references cited herein, 1972.

34. Thal LJ, Fuld PA, Masur DM and Sharpless NS: Oral physostigmine and lecithin improve memory in alzheimer disease. Ann Neurol 13: 491-496, 1983

35. Coelho F and Birks J: Physostigmine for Alzheimer's disease. Cochrane Database Syst Rev 2: CD001499, 2001.

36. Karis JH, Nastuk WL and Katz RL: The action of tacrine on neuromuscular transmission: A comparison with hexafluorenium. Brit J Anaesth 38: 762-774, 1966.

37. Harel M, Schalk I, Ehret-Sabatier L, Bouet F, Goeldner M, Hirth C, Axelsen PH, Silman I and Sussman JL: Quaternary ligand binding to aromatic residues in the active-site gorge of acetylcholinesterase. Proc Natl Acad Sci USA 90: 9031-9035, 1993.
38. Fernández-Bachiller MI,Pérez C, González-Muñoz GC, Conde S, López MG, Villarrova M, García AG and Rodríguez-Franco MI: Novel tacrine-8-hydroxyquinoline hybrids as multifunctional agents for the treatment of Alzheimer's disease, with neuroprotective, cholinergic, antioxidant and coppercomplexing properties. J Med Chem 53: 4927-4937, 2010.

39. Farlow M, Gracon SI, Hershey LA, Lewis KW, Sadowsky CH and Dolan-Ureno J: A controlled trial of tacrine in Alzheimer's disease. The tacrine study group. JAMA 268: 2523-2529, 1992.

40. Watkins PB, Zimmerman HJ, Knapp MJ, Gracon SI and Lewis KW: Hepatotoxic effects of tacrine administration in patients with Alzheimer's disease. JAMA 271: 992-998, 1994

41. Rogers SL, Farlow MR, Doody RS, Mohs R and Friedhoff LT: A 24 week double blind placebo controlled trial of donepezil in patients with Alzheimer's disease. Donepezil study group. Neurology 50: 136-145, 1998.

42. Jacobson SA and Sabbagh MN: Donepezil: Potential neuroprotective and disease-modifying effects. Expert Opin Drug Metab Toxicol 4: 1363-1369, 2008

43. Kryger G, Silman I and Sussman JL: Structure of acetylcholinesterase complexed with E2020 (Aricept): Implications for the design of new anti-Alzheimer drugs. Struct 7: 297-307, 1999.

44. Inglis F: The tolerability and safety of cholinesterase inhibitors in the treatment of dementia. Int J Clin Pract Suppl 127: 45-63, 2002.

45. Onor ML, Trevisiol M and Aguglia E: Rivastigmine in the treatment of alzheimer's disease: An update. Clin Interv Aging 2: $17-32,2007$

46. Corey-Bloom J, Anand $\mathrm{R}$ and Veach J: A randomized trial evaluating the efficacy and safety of ENA 713 (rivastigmine tartrate), a new acetylcholinesterase inhibitor, in patients with mild to moderately severe Alzheimer's disease. Int J Geriatr Psychopharmacol 1: 55-65, 1998.

47. Fraser MD, Davies JR and Chang X: New gold in them thar hills: Testing a novel supply route for plant-derived galanthamine. J Alzheimers Dis 55: 1321-1325, 2017.

48. de Souza FM, Busquet N, Blatner M, Maclean KN and Restrepo D: Galantamine improves olfactory learning in the Ts65Dn mouse model of down syndrome. Sci Rep 1: 137, 2011.

49. Pernov KG: Nivalin and its curative effect on disease of the nervous system. Psychiatr Neurol Med Psychol (Leipz) 13: 416-420, 1961 (In German).

50. Tariot PN, Solomon PR, Morris JC, Kershaw P, Lilienfeld S and Ding C: A 5-month, randomized, placebocontrolled trial of galantamine in AD. The Galantamine USA-10 Study Group. Neurology 54: 2269-2276, 2000.

51. Mehta M, Adem A and Sabbagh M: New acetylcholinesterase inhibitors for Alzheimer's disease. Int J Alzheimers Dis 2012: 728983, 2012.

52. Nordgren I, Bengtsson E, Holmstedt B and Pettersson BM: Levels of metrifonate and dichlorvos in plasma and erythrocytes during treatment of schistosomiasis with Bilarcil. Acta Pharmacol Toxicol (Copenh) 49 (Suppl 5): S79-S86, 1981.

53. Cummings JL, Cyrus PA, Bieber F, Mas J, Orazem J and Gulanski B: Metrifonate treatment of the cognitive deficits of Alzheimer's disease. The metrifonate study group. Neurology 50: 1214-1221, 1998.

54. Klein J: Phenserine. Exp Opin Investig Drugs 16: 1087-1097, 2007.

55. Greig NH, De Micheli E, Holloway HW, Yu QS, Utsuki T, Perry TA, Brossi A, Ingram DK, Deutsch J, Lahiri DK and Soncrant TT: The experimental Alzheimer drug phenserine: Preclinical pharmacokinetics and pharmacodynamics. Acta Neurol Scand Suppl 176: 74-84, 2000.

56. Thatte U: Phenserine Axonyx. Curr Opin Investig Drugs 6: 729-739, 2005.

57. Winblad B, Giacobini E, Frölich L, Friedhoff LT, Bruinsma G, Becker RE and Greig NH: Phenserine efficacy in Alzheimer's disease. J Alzheimer's Dis 22: 1201-1208, 2010.

58. Tweedie D, Fukui K, Li Y, Yu QS, Barak S, Tamargo IA, Rubovitch V, Holloway HW, Lehrmann E, Wood WH III, et al: Cognitive impairments induced by concussive mild traumatic brain injury in mouse are ameliorated by treatment with phenserine via multiple non-cholinergic and cholinergic mechanisms. PLoS One 11: e0156493, 2016.

59. Becker RE, Greig NH, Lahiri DK, Bledsoe J, Majercik S, Ballard C, Aarsland D, Schneider LS, Flanagan D, Govindarajan R, et al: (-)-Phenserine and inhibiting apoptosis: In pursuit of a novel intervention for Alzheimer's disease. Curr Alzheimer Res 15: 883-891, 2018. 
60. Luo W, Yu QS, Zhan M, Parrish D, Deschamps JR, Kulkarni SS Holloway HW, Alley GM, Lahiri DK, Brossi A and Greig NH: Novel anticholinesterases based on the molecular skeletons of furobenzofuran and methanobenzodioxepine. J Med Chem 48: 986-994, 2005.

61. Yu QS, Holloway HW, Luo W, Lahiri DK, Brossi A and Greig NH: Long-acting anticholinesterases for myasthenia gravis: Synthesis and activities of quaternary phenylcarbamates of neostigmine, pyridostigmine and physostigmine. Bioorg Med Chem 18: 4687-4693, 2010

62. Kamal MA, Greig NH, Alhomida AS and Al-Jafari AA: Kinetics of human acetylcholinesterase inhibition by the nove experimental Alzheimer therapeutic agent, tolserine. Biochem Pharmacol 60: 561-570, 2000.

63. Fürst S,Friedmann T,Bartolini A,Bartolini R, Aiello-Malmberg P, Galli A, Somogy GT and Knoll J: Direct evidence that eseroline possesses morphine-like effects. Eur J Pharmacol 83: 233-241, 1982.

64. Galli A, Renzi G, Grazzini E, Bartolini R, Aiello-Malmberg P and Bartolini A: Reversible inhibition of acetylcholinesterase by eseroline, an opioid agonist structurally related to physostigmine (eserine) and morphine. Biochemical Pharmac 31: 1233-1238, 1982.

65. Zhan ZJ, Bian HL, Wang JW and Shan WG: Synthesis of physostigmine analogues and evaluation of their anticholinesterase activities. Bioorg Med Chem Letts 20: 1532-1534, 2010.

66. Wang Y, Zeng QG, Zhang ZB, Yan RM, Wang LY and Zhu D: Isolation and characterization of endophytic huperzineA-producing fungi from Huperzia serrata. J Ind Microbiol Biotechnol 38: 1267-1278, 2011.

67. Camps P, El Achab R, Morral J, Muñoz-Torrero D, Badia A, Baños JE, Vivas NM, Barril X, Orozco M and Luque FJ: New tacrine-huperzine A hybrids (huprines): Highly potent tight-binding acetylcholinesterase inhibitors of interest for the treatment of alzheimer's disease. J Med Chem 43: 4657-4666, 2000.

68. Dvir H, Jiang HL, Wong DM, Harel M, Chetrit M, He XC, Jin GY, Yu GL, Tang XC, Silman I, et al: X-ray structures of Torpedo californica acetylcholinesterase complexed with (+)-huperzine A and (-)-huperzine B: Structural evidence for an active site rearrangement. Biochem 41: 10810-10818, 2002.

69. Li J, Wu HM, Zhou RL, Liu GJ and Dong BR: Huperzine A for alzheimer's disease. Cochrane Database of Syst Rev: CD005592, 2008

70. Guo AJ, Xie HQ, Choi RC, Zheng KY, Bi CW, Xu SL, Dong TTX and Tsim KW: Galangin, a flavonol derived from Rhizoma Alpiniae officinarum, inhibits acetylcholinesterase activity in vitro. Chem Biol Interact 187: 246-248, 2010.

71. de Paula AA, Martins JB, dos Santos ML, Nascente Lde C, Romeiro LA, Areas TF, Vieira KS, Gambôa NF, Castro NG and Gargano R: New potential AChE inhibitor candidates. Eur J Med Chem 44: 3754-3759, 2009.

72. Taiwo EA: Cashew nut shell oil - A renewable and reliable petrochemical feedstock. In: Advances in Petrochemicals. Patel V (ed). 2015 .

73. Piazzi L,Rampa A,Bisi A, Gobbi S,BellutiF,Cavalli A,Bartolini M, Andrisano V, Valenti P and Recanatini M: 3-(4-[[Benzyl (methyl)aminolmethyl]phenyl)-6,7-dimethoxy-2H-2-chromenone (AP2238) inhibits both acetylcholinesterase and acetylcholinesterase-induced beta-amyloid aggregation: A dual function lead for Alzheimer's disease therapy. J Med Chem 46: 2279-2282, 2003.

74. Rizzo S, Bartolini M, Ceccarini L, Piazzi L, Gobbi S, Cavalli A, Recanatini M, Andrisano V and Rampa A: Targeting Alzheimer's disease: Novel indanone hybrids bearing a pharmacophoric fragment of AP2238. Bioorg Med Chem 18: 1749-1760, 2010.

75. Pi R, Xuexuan MX, Chao X, Cheng Z, Liu M, Duan X, Ye M, Chen X, Mei Z, Liu P, et al: Tacrine-6-ferulic acid, a novel multifunctional dimer, inhibits amyloid- $\beta$-mediated Alzheimer's disease-associated pathogenesis in vitro and in vivo. PLoS One 7: e31921, 2012.

76. Tipton KF, Boyce S, O'Sullivan J, Davey GP and Healy J: Monoamine oxidases: Certainties and uncertainties. Curr Med Chem 11: 1965-1982, 2004.

77. Edmondson DE, Mattevi A, Binda C, Li M and Hubálek F: Structure and mechanism of monoamine oxidase. Curr Med Chem 11: 1983-1993, 2004.

78. Pachón-Angona I, Refouvelet B, Andrýs R, Martin H, Luzet V, Iriepa I, Moraleda I, Diez-Iriepa D, Oset-Gasque MJ, Marco-Contelles J, et al: Donepezil + chromone + melatonin hybrids as promising agents for Alzheimer's disease therapy. J Enzyme Inhib Med Chem 34: 479-489, 2019.
79. Chufarova N, Czarnecka K, Skibiński R, Cuchra M, Majsterek I and Szymański P: New tacrine-acridine hybrids as promising multifunctional drugs for potential treatment of Alzheimer's disease. Arch Pharm Chem Life Sci 351: e1800050, 2018

80. Lopes JPB, Silva L, da Costa Franarin G, Antonio Ceschi M, Seibert Lüdtke D, Ferreira Dantas R, de Salles CMC, Paes Silva-Jr F, Roberto Senger M, Alvim Guedes I and Emmanuel Dardenne L: Design synthesis, cholinesterase inhibition and molecular modelling study of novel tacrine hybrids with carbohydrate derivatives. Bioorg Med Chem 26: 5566-5577, 2018.

81. Zhu J, Yang H, Chen Y, Lin H, Li Q, Mo J, Bian Y, Pei Y and Sun H: Synthesis, pharmacology and molecular docking on multifunctional tacrine-ferulic acid hybrids as cholinesterase inhibitors against Alzheimer's disease. J Enzym Inhib Med Chem 33: 496-506, 2018.

82. Korabecny J, Musilek K, Holas O, Binder J, Zemek F, Marek J, Pohanka M, Opletalova V, Dohnal V and Kuca K: Synthesis and in vitro evaluation of $\mathrm{N}$-alkyl-7-methoxytacrine hydrochlorides as potential cholinesterase inhibitors in Alzheimer disease. Bioorg Med Chem Lett 20: 6093-6105, 2010

83. Ali MA, Yar MS, Hasan MZ, Ahsan MJ and Pandian S: Design, synthesis and evaluation of novel 5,6-dimethoxy-1-oxo-2,3dihydro-1H-2-indenyl-3,4-substituted phenyl methanone analogues. Bioorg Med Chem Letts 19: 5075-5077, 2009.

84. De la Torre P, Saavedra LA, Caballero J, Quiroga J, Alzate-Morales JH, Cabrera MG and Trilleras J: A novel class of selective acetylcholinesterase inhibitors: Synthesis and evaluation of (E)-2-(benzo d]thiazol-2-yl)-3-heteroarylacrylonitriles. Molecules 17: 12072-12085, 2012.

85. Weinreb O, Amit T, Bar-Am O and Youdim MBH: A novel anti-Alzheimer's disease drug, ladostigil, neuroprotective, multimodal brain-selective monoamine oxidase and cholinesterase inhibitor. Int Rev Neurobiol 100: 191-215, 2011.

86. Yazdani M, Edraki N, Badri R, Khoshneviszadeh M, Iraji A and Firuzi O: Multi-target inhibitors against Alzheimer disease derived from 3-hydrazinyl 1,2,4-triazine scaffold containing pendant phenoxy methyl-1,2,3-triazole: Design, synthesis and biological evaluation. Bioorg Chem 84: 363-371, 2019.

87. Rastegari A, Nadri H, Mahdavi M, Moradi A, Mirfazli SS, Edraki N, Moghadam FH, Larijani B, Akbarzadeh T and Saeedi M: Design, synthesis and anti-Alzheimer's activity of novel 1,2,3-triazole-chromenone carboxamide derivatives. Bioorg Chem 83: 391-1401, 2019.

88. Shah MS, Khan SU,Ejaz SA,Afridi S,Rizvi SUF,Najam-ul-HaqM and Iqbal J: Cholinesterases inhibition and molecular modeling studies of piperidyl-thienyl and 2-pyrazoline derivatives of chalcones. Biochem Biophys Res Commun 482: 615-624, 2017.

89. Reis J, Cagide F, Valencia ME, Teixeira J, Bagetta D, Pérez C, Uriarte E, Oliveira PJ, Ortuso F, Alcaro S, et al: Multi-target-directed ligands for Alzheimer's disease: Discovery of chromone-based monoamine oxidase/cholinesterase inhibitors. Eur J Med Chem 158: 781-800, 2018.

90. Li Q, He S, Chen Y, Feng F, Qu W and Sun H: Donepezil-based multi-functional cholinesterase inhibitors for treatment of Alzheimer's disease. Eur J Med Chem 158: 463-477, 2018.

91. Xie SS, Wang XB, Li JY, Yang L and Kong LY: Design, synthesis and evaluation of novel tacrine-coumarin hybrids as multifunctional cholinesterase inhibitors against Alzheimer's disease. Eur J Med Chem 64: 540-553, 2013.

92. Catto M, Pisani L, Leonetti F, Nicolotti O, Pesce P, Stefanachi A, Cellamare S and Carotti A: Design, synthesis and biological evaluation of coumarin alkylamines as potent and selective dual binding site inhibitors of acetylcholinesterase. Bioorg Med Chem 21: 146-152, 2013.

93. Khoobi M, Alipour M, Moradi A, Sakhteman A, Nadri H, Razavi SF, Ghandi M, Foroumadi A and Shafiee A: Design, synthesis, docking study and biological evaluation of some novel tetrahydrochromeno 3',4':5,6] pyrano 2,3-b] quinolin-6 $(7 \mathrm{H})$-one derivatives against acetyland butyrylcholinesterase. Eur J Med Chem 68: 291-300, 2013.

94. Jin P, Kim JA, Choi DY, Lee YJ, Jung HS and Hong JT: Anti-inflammatory and anti-amyloidogenic effects of a small molecule, 2,4-bis(p-hydroxyphenyl)-2-butenal in Tg2576 Alzheimer's disease mice model. J Neuroinflammation 10: 767-779, 2013.

95. Ramsay RR, Popovic-Nikolic MR, Nikolic K, Uliassi E and Bolognesi ML: A perspective on multi-target drug discovery and design for complex diseases. Clin Transl Med 7: 3, 2018. 